\title{
Gender Differences in the Experience and Report of LBP Among Adults Population in Nigeria
}

\author{
Odebiyi $\mathrm{DO}^{1 *}$, Akinpelu $\mathrm{AO}^{2}$, Balogun $\mathrm{S}^{3}$ and Alonge $\mathrm{TO}^{4}$ \\ ${ }^{1}$ Department of Physiotherapy, University of Lagos, Nigeria \\ ${ }^{2}$ Departments of Physiotherapy, University of Ibadan, Nigeria \\ ${ }^{3}$ Nigerian Back School, Nigeria \\ ${ }^{4}$ Department of Orthopaedic \& Trauma, University of Ibadan, Nigeria
}

Submission: July 18, 2018 ; Published: March 22, 2019

*Corresponding author: Odebiyi DO, Department of Physiotherapy, Faculty of Clinical Sciences, College of Medicine, University of Lagos, Nigeria

\begin{abstract}
Introduction: Low back pain (LBP) is one of the most prevalent musculoskeletal disorders and it is cited as one of the major reasons for hospital visits, hence, it has received considerable attention among scholars in Nigeria. However, there is limited data on how the experience of back pain varies for men and women in Nigeria, particularly following an intervention. Such knowledge could be vital in the assessment, treatment and outcome expectations in LBP management.
\end{abstract}

Aims: To explore gender difference in the experience of LBP among adults in Nigeria and to assess whether there was gender difference in recovery from LBP following these interventions.

Methods: A total of 130 adults with LBP participated in this study, they were randomised into two groups-Back School Group (BSG) and Control Group (CG). Both groups received physiotherapy and drug therapy for their LBP, in addition to this, the BSG participated in a back-care training programme and they were also given a 24-page back care handbook. The Mann-Whitney U test was used to explore gender differences in pain level at baseline and at four weeks period for the two groups.

Results: There were marked gender differences in LBP at baseline period for both groups; pain level was significantly $(\mathrm{P}<0.05)$ higher in women than men. This gender difference persists over four weeks of intervention but was only statistically significant for the control group $(\mathrm{P}<0.05)$. With the exemption of age group 30-39 for BSG and 50-59 for CG, women experience more LBP across the various age groups than men at baseline respectively. While this gender difference persists after week 4 in the CG, more men reported LBP in the BSG after week 4.

Conclusion: Women experienced a higher level of LBP before and after four weeks of intervention. This finding could be suggestive of the clinical relevance of gender in LBP management and may imply that care should be taken in managing LBP particularly among women to ensure pain is not under managed.

Keywords: Gender; Experience; Report of LBP; Adults; Nigeria

Abbreviations: LBP: Low back pain; BSG: Back school group; CG: Control group; RMDQ: Ronald Morris Disability Questionnaire; NLBP: Nonspecific low back pain; RMDQ: Ronald morris disability questionnaire; VAS: Visual analogue scale

\section{Introduction}

Low back pain (LBP) is among the most commonly reported symptoms, particularly in the adult population, and it exists in all cultures. It is the leading cause of activity limitation and work absenteeism $[1,2]$. Low back pain is a major problem in both lowand middle-income countries [3,4] and the main cause of years lived with disability in the world [5]. In Africa, the prevalence of LBP among the adult population has been estimated to be $32 \%$ [6]. Although it is often seen as a trivial problem compared to other afflictions that generate a high mortality, like cancer or infectious diseases. The causes of LBP range from heterogeneous specific and non-specific musculoskeletal disorders involving the vertebral column [7] however, the cause of most LBP is nonspecific $[8,9]$.
Research studies have suggested that the prevalence and report of pain intensity differ between males and females [10-13]. It appears that the females suffering from pain along the spine reported more pain when compared to their male counterparts [10]. It has been suggested that this may lead to under diagnosis and under treatment of pain in females [11] And invariably, this may likely lead to the experience of chronic pain among the females compared to males. Studies focusing on report of pain intensity and gender have reported that females are more likely to experience chronic pain and/or received testament for chronic pain compared to the males $[14,15]$. Although, it has been argued that gender is inconsequential in the presentation of chronic pain [16].There are various possible reasons for the reported gender 
difference in the experience and report of pain intensity between the males and females: It could be a reflection of the differences between males and females in their willingness to seek medical care; [10] cooping capability of the participants; or the possibility that clinicians respond differently to male and female patient [17] .Apart from physiological reasons, researchers have identified psychological factors that are related to gender, these include employment, marriage and depression[18,19]. Thus, gender evaluation of report and changes in pain over time is likely to be more clinically important; although it appears it is still not a routinely considered factor in empirical studies.

Studies have showed that there is something about the experience of being a man or a woman that needs to be identified [20] as this may influence treatment, treatment outcomes, and outcome measures. A consideration to these factors is therefore imperative. However, there is limited data on how the experience of LBP varies in men and women in Nigeria; such knowledge could be vital in the assessment, treatment, and outcome expectations of patients with LBP. Therefore, this study was designed to explore the gender difference in the experience of LBP among adults Nigerians. It also sought to assess whether there were gender differences in the recovery from LBP following intervention.

\section{Materials and Methods}

\section{Participants}

The participants in this study were patients with mechanical LBP who were newly referred to the physiotherapy Out-Patient Clinic of Orthopaedic Hospital in Nigeria. Only patients with no history of pathology causing the LBP and whose pain was influenced (i.e. made worst or better) by the McKenzie movement diagnosis tests [21] were recruited in the study.

\section{Study Sample}

The sample size was based on the average number of new patients with LBP per month referred to the physiotherapy department of the Orthopaedics Hospital between 12-months period of the study. Based on this, a sample seize of 150 was then proposed as the sample size for this study. A total of 160 patients were approached and only 130 of them agreed to participate in this study. This number is greater than the sample size of 45 estimated Table 1: Age and physical characteristics of the participants. using the sample size formula of Areole [22]. The participants were recruited consecutively as they became available and allocated alternatively to two groups of 65 each, the Back-School Group (BSG) and Control Group (CG). The aim and objective of the study which was contained in the consent information was provided for those who consented to participate in the study.

\section{Methods}

Prior to the commencement of the study, ethical approval was sought for and obtained from the joint University of Ibadan and University College Hospital Institutional Review Committee on human subject (Ref. No: UI/IRC/03/0068). The participants' weight and height were assessed. In addition to physiotherapy, the participants in the back-school group were shown the backschool documentary, in groups of between two to five as they became available. One of the researchers, difference from the one who administered treatment, went through the NBSM Handbook with each participant before giving the participants a copy each. The details of the NBSM documentary and the Handbook has been presented in a previous study [23]. Participants were also encouraged to go through the handbook regularly and apply to what they have learnt to their daily living activities. The participant had eight physiotherapy sessions for 4 weeks. Visual analogue scale VAS and Ronald Morris Disability Questionnaire (RMDQ) were used to assess participants in the two groups before and after the treat intervention.

\section{Results}

The participants in the gender categories were similar in age and other physical characteristics except for body mass index (Table 1). Women experienced a significantly $(\mathrm{P}<0.05)$ higher level of LBP at baseline for both groups. This gender difference was also present at week 4 but was only significant $(\mathrm{P}<0.05)$ for the control groups (Table 2). The treatment protocol administered for both back school group and control group were equally significant ( $p>0.05$ ) in reducing the participants' level of pain (Table 3). There was no gender difference $(\mathrm{P}>0.05)$ in the disability (RMDQ scores) at baseline and four weeks post intervention for participants in the back-school group; while there was a significant $(\mathrm{p}<0.05)$ gender difference in disability at baseline and week four for participants in the control group (Table 4).

\begin{tabular}{|c|c|c|c|c|}
\hline All Participants Mean \pm Sd & Male Mean \pm Sd & Female Mean \pm Sd & T & -0.179 \\
\hline Age & $47.86 \pm 12.11$ & $48.04 \pm 11.33$ & 8.567 & 0.858 \\
\hline Height & $1.68 \pm 0.08$ & $1.63 \pm 0.06$ & -0.518 & $0.001^{*}$ \\
\hline Weight & $76.24 \pm 13.26$ & $75.66 \pm 14.10$ & -3.04 & 0.605 \\
\hline BMI & $27.11 \pm 4.79$ & $28.29 \pm 5.19$ & \\
\hline *Significant at $p<0.05$ & \multicolumn{3}{l}{} \\
\hline
\end{tabular}

Table 2: Gender difference in the experience/report of low back pain intensity (VAS scores) for the participants.

\begin{tabular}{|c|l|c|c|c|}
\hline Group & Period & Male Mean \pm Sd & Female Mean \pm Sd & P-Value \\
\hline Back School Group $(\mathrm{n}=65)$ & Baseline VAS & $5.56 \pm 1.79$ & $6.46 \pm 1.99$ & $0.046^{*}$ \\
\hline (Male=39; Female=26) & Week 4 VAS & $1.59 \pm 1.46$ & $1.77 \pm 1.80$ & 0.831 \\
\hline
\end{tabular}


Journal of Yoga and Physiotherapy

\begin{tabular}{|c|c|c|c|c|}
\hline Control Group (n=65) & Baseline VAS & $5.61 \pm 2.23$ & $6.90 \pm 1.97$ & $0.026^{*}$ \\
\hline (Male=23; Female=42) & Week 4 VAS & $4.87 \pm 2.26$ & $4.98 \pm 2.20$ & 0.939 \\
\hline *Significant at $\mathrm{p}<0.05$ &
\end{tabular}

Table 3: Wilcoxon Signed rank test of the difference between baseline and week 4 VAS for both groups.

\begin{tabular}{|c|c|c|c|}
\hline Group & Baseline VAS Mean \pm Sd & Week 4 VAS Mean \pm Sd & P-value \\
\hline Back School Group (n=65) & $5.92 \pm 1.906$ & $1.66 \pm 1.594$ & $0.001^{*}$ \\
\hline Control Group (n=65) & $6.45 \pm 2.144$ & $1.51 \pm 1.687$ & $0.001^{*}$ \\
\hline
\end{tabular}

Table 4: Gender difference in disability i.e. Roland Morris Disability Questionnaire (RMDQ) for back school and control groups.

\begin{tabular}{|c|c|c|c|c|}
\hline Group & Period & Male & Female & P-value \\
\hline Back School Group (n=65) & Baseline RMDQ & $38.46 \pm 20.22$ & $43.43 \pm 23.16$ & 0.452 \\
\hline (Male=39; Female=26) & Week 4 RMDQ & $10.48 \pm 12.36$ & $9.62 \pm 11.17$ & 0.76 \\
\hline & Change in RMDQ & $27.99 \pm 0.76$ & $33.82 \pm 18.65$ & 0.138 \\
\hline Control Group (n=65) & Baseline RMDQ & $36.25 \pm 20.73$ & $50.47 \pm 22.42$ & $0.021^{*}$ \\
\hline (Male=23; Female=42) & Week 4 RMDQ & $6.53 \pm 9.39$ & $12.11 \pm 13.42$ & $0.038^{*}$ \\
\hline & Change in RMDQ & $29.72 \pm 9.35$ & $38.36 \pm 23.41$ & 0.149 \\
\hline \multicolumn{3}{r}{} \\
\end{tabular}

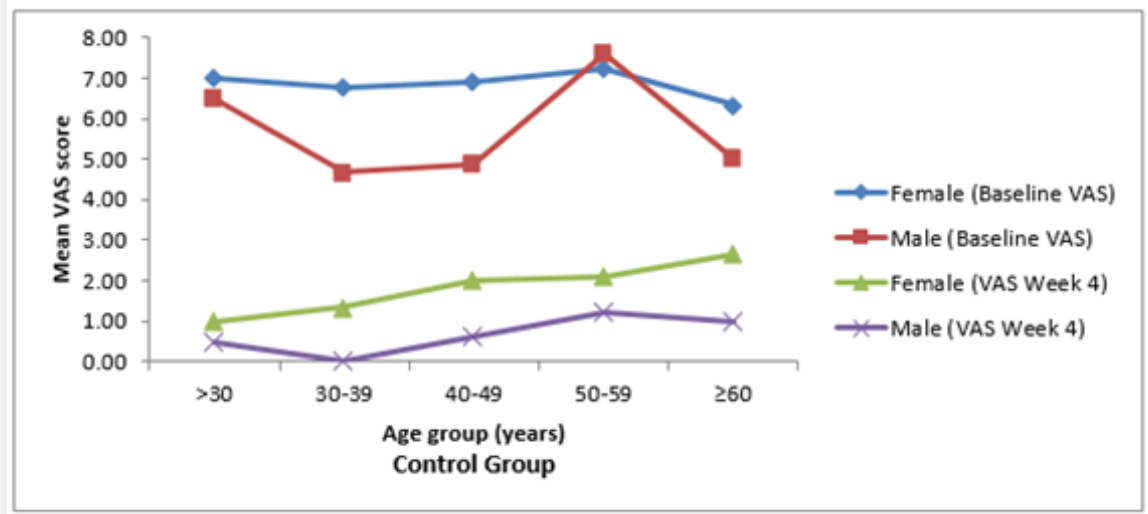

Figure 1: Pre-and post-intervention Gender experience back pain in the control group per age distribution.

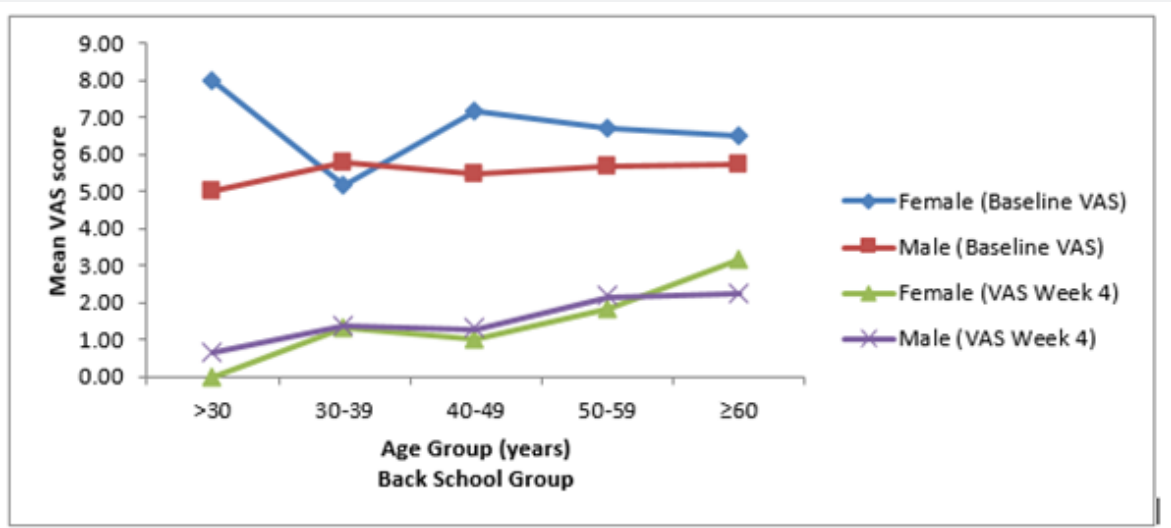

Figure 2: Pre-and post-intervention Gender experience back pain in the Back-School Group per age distribution.

The results showed that women experience a higher level of back pain across the various age groups than men, with the exemption of age 50-59 for participant at baseline in the control group; this gender difference persists after week 4 (Figure 1). Also, with the exemption of age group 30-39, women experience a higher level of pain than men at baseline, for participant in the back-school group; however, contrary to observation from the control group, more men experienced a higher level of pain than women at 4-weeks post intervention. It appeared as if back school was beneficial for women in most age groups (Figure 2). 


\section{Discussion}

This study was designed in response to the observed limited data on how the experience of non-specific low back pain (NLBP) varies for men and women in Nigeria, particularly before and following non-pharmacological intervention. Such knowledge may be vital in the assessment, treatment and outcome expectations of patients with NLBP. Thus, this sought to explore gender differences in the experience of LBP among adults in Nigeria and to assess whether there were gender differences in recovery from LBP following these interventions.

The finding of this study revealed that there was a significant difference in the experience of pain (baseline VAS scores) between the women and men at baseline i.e. before intervention, irrespective of the treatment intervention. This suggests that there is a gender difference in the experience of LBP among the participants, with women experiencing more LBP than the men before intervention. The finding of this study is in line with the trend in the literature and it agrees with the finding of Peterson et al. [13] who in a study exploring the gender differences in pain levels before and after treatment of selected musculoskeletal complaints reported that women reported significantly higher baseline LBP level before Chiropractic treatment. Other studies have also documented that women generally report higher pain intensity compared to men $[12,14,24]$. Studies have shown that men have more diffuse noxious inhibitory controls compared to women [15,25].

This finding could be suggestive of the clinical relevance of gender in LBP management and may imply that care should be taken in managing LBP particularly among women to ensure the pain is not under managed. Low back pain under management may lead to chronicity more in women than men, if this factor is taking into consideration when treating patients with low back pain. Invariably, this may amount to treating women with LBP differently from men. The results showed that women experience a higher level of LBP across the various age groups than men, with the exemption of age 50-59 for participant at baseline in the control group; this gender difference persists after week 4 . Also, with the exemption of age group 30-39, women experience a higher level of pain than men at baseline, for participant in the back-school group; however, contrary to observation from the control group, more men experienced a higher level of pain than women at 4-weeks post intervention. It appeared as if back school was beneficial for women in most age groups.

Interestingly, this observed gender differences did not lead to differences in the disability status of the participants at baseline; as there was no gender difference in the disability (RMDQ scores) at baseline. However, four weeks after intervention, there was a significant difference in the disability (RMDQ scores) observed in the participants in the control group. The finding of this study suggests that women response to non-pharmacological treatment differently when compared to men, and that this may be particularly influenced by the type of intervention employed. Thus, women with LBP may require different intervention when compared to men, particularly when using certain manual therapy modalities (intervention). Anecdotal evidence, from personal observation in the clinic, suggests that the treatment men with LBP may require modification when used for women with LBP. Also, more women in the control group were found to exhibit improvement in pain-related disability than men. This finding corroborates the finding of Pieh et al. [26] who in the result of a study from a 5-week multimodal pain management programme found that women exhibited an improvement more in painrelated disability as compared with men.

Although, gender difference was also present after four weeks, but was only significant for participants in the control groups; when the women still experience more pain relative to the men. This may suggest that gender may be a function of the intervention; combined back school, convectional physiotherapy and drug therapy appeared to bridge the suggested gender difference in the treatment of patients with LBP. There are possible limitations to this study; one of which is the fact that only patients presenting for specific treatments involving nonspecific LBP were included in this study. Extrapolation of the obtained to other musculoskeletal discomforts of other part of the body or treatments cannot be done without additional research. Also, specific diagnoses of the causes of the LBP, or consideration of other demographic variables/factors like duration of pain, ethnicity, work status, body mass index, and level of physical activity were not really considered when recruiting participants into the study; further research may be needed to control some of these factors in other to obtain the true picture of the gender differences for patients with non-specific LBP.

\section{Conclusion and Recommendation}

Finding from this study revealed that women experienced a higher level of LBP before and after four weeks of intervention. While this observed gender differences did not lead to differences in the disability status of the participants at baseline, there was a significant difference in the disability status of the participants in the control group. The finding from this study also suggests that back school was beneficial for women in most age groups. This may suggest the clinical relevance of gender in LBP management and may imply that care should be taken in managing LBP particularly among women to ensure pain is not under managed. And that woman with LBP may benefit more when treated differently from their male counterpart with similar presentation's. It may also reduce the chances of developing chronicity more in women.

\section{References}

1. Dionne CE, Dunn KM, Croft PR (2006) Does back pain prevalence really decrease with increasing age? A systematic review. Age and Ageing 35(3): 229-234.

2. Rapoport J, Jacobs P, Bell NR, Klarenbach S (2004) Refining the measurement of the economic burden of chronic diseases in Canada. Chronic Dis Can 25(1): 13-21. 
3. Jin K, Sorock GS, Courtney TK (2004) Prevalence of low back pain in three occupational groups in Shanghai, People's Republic of China. Journal of Safety Research 35(1): 23-28.

4. Hoy D, March L, Brooks P, Woolf A, Blyth F, et al. (2010) Measuring the global burden of low back pain. Best Practice and Research. Clinical Rheumatology 24(2): 155-165.

5. Vos T, Flaxman AD, Naghavi M, Lozano R, Michaud C, et al. (2012) Years lived with disability (YLDs) for 1160 sequelae of 289 diseases and injuries 1990 - 2010: a systematic analysis for the global burden of Diseases study 2010. Lacent 380(9859): 2163- 2196.

6. Louw QA, Morris LD, Grimmer SK (2007) The prevalence of low back pain in Africa: a systematic review. BMC Musculoskelet Disorders 8: 105.

7. Walsh $\mathrm{T}(2000)$ The Oswestry Disability Index: point of view. Spine 25 2953.

8. Iyer RS, Thapa MM, Chew FS (2011) Chronic recurrent multifocal osteomyelitis: review. AJR Am J Roentgenol 196(6 Suppl): S87-S91.

9. Balagué F, Mannion AF, Pellisé F, Cedraschi C (2012) Non-specific low back pain. Lancet 379: 482-491.

10. LeResche L (2011) Defining gender disparities in pain management. Clin Orthop Relat Res 469(7): 1871-1877.

11. Pizzo P, Clark N (2011) Relieving pain in America: A blueprint for transforming prevention, care, education, and research. Washington: DC, National Academies Press, USA.

12. Ruau D, Liu LY, Clark JD, Angst MS, Butte AJ (2011) Sex differences in reported pain across 11,000 patients captured in electronic medical records. The Journal of Pain 13(3): 228-234.

13. Odebiyi DO, Akinpelu AO, Alonge TO, Adegoke BOA (2009) Back School: The development of a Nigerian Back School Model. Quarterly Journal of hospital Medicine 19: 135-141.

14. Rustøen T, Wahl AK, Hanestad BR, Lerdal A, Paul S, et al. (2004) Gender differences in chronic pain-Findings from a population-based study of Norwegian adults. Pain Manag Nurs 5(3): 105-117.

15. Fillingim RB, King CD, Ribeiro-Dasilva MC, Rahim WB, Riley JL (2009)
Sex, gender, and pain: a review of recent clinical and experimental findings. J Pain 10(5): 447-485.

16. Turk DC, Okifuji A (1999) A cognitive-behavioural approach to pain management. In: Wall PD, Melzack R (Eds.), Textbook of Pain. Edinburgh: Churchill Livingstone, London, United Kingdom, pp. 1431-1443.

17. Miaskowski C (1999) The role of sex and gender in pain perception and responses to treatment. In: Gatchel RJ, Turk DC (Eds.), Psychosocial factors in pain: Critical perspectives Guilford Press, New York, USA, pp. 401-411.

18. Meana M (1998) The meeting of pain and depression: Comorbidity in women. Canadian Journal of Psychiatry 43(9): 893-899.

19. Sheffer CE, Cassisi JE, Ferraresi LM, Lofland KR, McCarcken LM (2002) Sex difference in the presentation of Chronic Low Back Pain. Psychology of Woman Quarterly 26(4): 329-340.

20. Fagley NS, Miller PM (1990) Investigating and reporting sex differences: Methodological importance, the forgotten consideration. American Psychologist 45: 297-298.

21. McKenzie RA (1981) The Lumbar Spine: Mechanical Diagnosis and Therapy. Wellington, Spinal Publications Limited, New Zealand.

22. Araoye MO (2003) Data processing and analysis Research methodology with statistics for health and social sciences Nathadex publishers, Ilorin, Nigeria, pp. 160-163.

23. Peterson CK, Bolton J, Humphreys BK (2012) Predictors of improvement in acute and chronic low back pain patients undergoing chiropractic treatment. J Manipulative Physiol Ther 35(7): 525-533.

24. Bingefors K, Isacson D (2004) Epidemiology, co-morbidity, and impact on health-related quality of life of self-reported headache and musculoskeletal pain--a gender perspective. Eur J Pain 8(5): 435-450.

25. Popescu A, LeResche L, Truelove EL, Drangsholt MT (2010) Gender differences in pain modulation by diffuse noxious inhibitory controls: a systematic review. Pain 150(2): 309-318.

26. Pieh C, Altmeppen J, Neumeier S, Loew T, Angerer M (2012) Gender differences in outcomes of a multimodal pain management program. Pain 153(1): 197-202.

\begin{tabular}{l} 
Your next submission with Juniper Publishers \\
will reach you the below assets \\
- Quality Editorial service \\
- Swift Peer Review \\
- Reprints availability \\
- E-prints Service \\
- Manuscript Podcast for convenient understanding \\
- Global attainment for your research \\
- Manuscript accessibility in different formats \\
( Pdf, E-pub, Full Text, Audio) \\
- Unceasing customer service \\
Track the below URL for one-step submission \\
https://juniperpublishers.com/online-submission.php \\
\hline
\end{tabular}

